\title{
Phoneme-monitoring reaction time and preceding prosody: Effects of stop closure duration and of fundamental frequency
}

\author{
ANNE CUTLER and CHRISTOPHER J. DARWIN \\ University of Sussex, Brighton BN1 9QG, England
}

\begin{abstract}
In an earlier study, it was shown that listeners can use prosodic cues that predict where sentence stress will fall; phoneme-monitoring RTs are faster when the preceding prosody indicates that the word bearing the target will be stressed. Two experiments which further investigate this effect are described. In the first, it is shown that the duration of the closure preceding the release of the target stop consonant burst does not affect the $\mathrm{RT}$ advantage for stressed words. In the second, it is shown that fundamental frequency variation is not a necessary component of the prosodic variation that produces the predicted-stress effect. It is argued that sentence processing involves a very flexible use of prosodic information.
\end{abstract}

Speakers rarely assign equal weight to each word of a sentence. Almost invariably, one word, or a very few words, will be spoken with higher stress than the others. These emphasized words are singled out for reasons connected with the meaning of the sentence ${ }^{1}$; thus primary stress may be placed so as to focus on the semantically most central portions of a sentence, to highlight the contrast between two parts of a sentence, or to de-stress a word that has been mentioned earlier. A shift in sentence stress location can result in a change in the sentence's meaning (compare "Lou called Terry an academic and then she abused him" with highest stress on the final verb or on the pronouns); therefore it is important for a listener to identify the location of sentence stress in order to understand the speaker's message.

An earlier study (Cutler, 1976) on the processing of sentence stress indicated that listeners make considerable use of prosodic information which serves to predict where sentence stress will fall. This study used the phoneme-monitoring task, in which the subjects listen to a sentence and press a button as soon as they hear a word beginning with a specified consonant; reaction time ( $R T)$ in this task is known to be faster to target consonants in words that bear sentence stress than to targets in words that do not (Cutler \& Foss, 1977; Shields, McHugh, \& Martin, 1974). When acoustically identical target-bearing words occurred in contexts that were identical in all respects except in prosody, one having been originally read with high stress at the point at which the target occurred, and the other with low, the targets in "high-stress" contexts elicited faster RTs than the targets in "low-stress"

This research was supported by grants from the Science Research Council. Requests for reprints should be addressed to esther author at The Laboratory of Experimental Psychology, University of Sussex, Brighton BN1 9QG, England. contexts. There were no acoustic differences between the target words themselves which could account for this result; the only difference between the contexts lay in the prosody. It was concluded, therefore, that the prosodic context had contained cues predicting that sentence stress would occur at the location of the target in the "high-stress" case, and elsewhere in the "low-stress" case, and that listeners had been making use of these cues in order-it was argued-to direct their attention to the words that were most highly stressed.

Since sentence stress location intimately reflects the semantic structure of the sentence, with the most highly stressed words being in general the semantically most central part of the utterance, direction of attention towards words bearing sentence stress could usefully facilitate the comprehension of sentence meaning. Indeed, Cutler and Fodor (1979) reported an experiment in which an analogous effect on phonememonitoring RTs was obtained by holding prosody constant and varying the location of sentence focus and argued, on this basis, that the use of predictive cues to high stress is best understood as the use of cues to focused or semantically highlighted information in the sentence.

The present paper describes two further experiments using the splicing paradigm developed by Cutler (1976). These experiments address the question of the nature of the prosodic information which enables listeners to direct attention towards upcoming highly stressed words.

\section{EXPERIMENT 1 EFFECTS OF STOP CLOSURE DURATION}

In the Cutler (1976) study, the original target-bearing words, each spoken once with high and once with low 
stress, had been spliced out of their sentence contexts and replaced by identical copies of the same word taken from another reading of the same matrix sentence in which neither particularly high nor particularly low stress had been assigned to the target word. The tapes were spliced by hand, and the word-initial splices were made as close as possible to the release of the stop consonant burst (all target words began with $/ \mathrm{b} /, / \mathrm{d} /$, or $/ \mathrm{k} /$ ), because the bursts were relatively easy to locate.

This procedure, however, meant that the closure before the burst in the spliced sentences and in the original sentences was of the same duration (or roughly the same, because hand splicing is bound to have introduced some imprecision). In 18 of the 20 spliced sentences, as it turned out, the stop closure duration was longer in the "high-stress" version than in the "low-stress" version, reflecting the fact that in the original recordings stop consonants preceding stressed vowels had longer closures than stops preceding unstressed vowels. The largest "high" minus "low" closure duration advantage was $57 \mathrm{msec}$ and the mean advantage was $31 \mathrm{msec}$.

This difference in closure duration raises the possibility that the effective component of the preceding prosody which led to the RT difference found in the Cutler (1976) study might have been the 10th of a second or so immediately preceding the target sound. ${ }^{2}$ The additional closure duration in the "high-stress" case could, for instance, have served as a more effective acoustic cue to the identity of the consonant. Alternatively, it might simply have provided a little extra processing time, so that, by the time the target word was uttered, processing of the preceding word and of the implosive transitions into the stop closure had proceeded further and processing of the target word could begin earlier. (Exactly this processing time argument is used by Mehler, Segui, and Carey, 1978, and Newman and Dell, 1978, to account for the RT advantage of target words preceded by polysyllabic as opposed to monosyllabic words.)

Accordingly, Experiment 1 was carried out to test the effects of stop closure duration on the RT advantage of "stressed" over "unstressed" words in phoneme monitoring. The duration of the stop closure was varied by manipulating the position at which the wordinitial splices were made during replacement of the original high- and low-stress target words by the acoustically identical neutral-stress versions of the same words. Targets spliced at the onset of the burstin which the spliced sentences preserved the closure durations of the original recordings-were compared with targets spliced at the onset of the closure. Those spliced at the burst thus tended to have longer closures before "high-stress" words, while those spliced at closure had identical closure durations in the "high-" and "low-stress" conditions; if stop closure duration was responsible for the original finding, then there should be no RT advantage for "high-stress" targets in the sentences spliced at stop closure.

\section{Method}

Materials. The 20 experimental sentences listed in Appendix 1 are essentially the same sentences used by Cutler (1976), with a few minor wording changes and the replacement of one sentence to bring them in line with British English usage.

Each sentence was recorded in three versions: once with high stress falling on the word bearing the target sound, once with reduced stress on that word, and once in a neutral version with no contrastive or emphatic stresses. (In order to make the prosodic contours sound natural, the three versions had different endings; however, the point at which the versions diverged was at least two and an average of five syllables beyond the occurrence of the target.) The recording was made by a male speaker of British English in a sound-attenuated cubicle. The speaker knew the purpose of the experiment and read the sentences at a fast-normal speed in such a way as to make the position of the sentence stress clearly apparent.

All three versions of each sentence were low-pass filtered at $3.5 \mathrm{kHz}$ and digitized at $8 \mathrm{kHz}$ to 10 bits. The spliced sentences to be used in the experiment were prepared with the aid of a waveform editing program, written by the second author, which allowed splicing to within one sample. The target word was spliced out of each version of each sentence in two ways: once with the initial splice made at the release of the stop burst and once with the initial splice made at the onset of the stop closure; the second splice was made in each case at the end of the target word. Four versions of each experimental sentence were then created: (1) the high-stress matrix sentence from which the target word starting from the burst release had been spliced out and replaced with the neutral-stress target word spliced at the burst release; (2) the same high-stress matrix sentence with the target word starting from the closure onset spliced out and replaced with the neutral-stress target word spliced at the closure onset; and (3) and (4) the two corresponding low-stress versions. In the burst-splice condition, 16 of the 20 experimental sentences had longer closures in the "highstress" than in the "low-stress" version, with the largest "high" minus "low" advantage being $69 \mathrm{msec}$ and the mean advantage 26 msec. Figure 1 illustrates the two alternative word-initial splicing positions.

The digital files of the spliced sentences were then modified so that, on playback, a click would appear on a second channel coincident with the release of the word-initial stop on the speech channel. This click, inaudible to the subjects, was used to start the reaction timers, ensuring that timing started precisely at stoprelease.

Four experimental tapes were constructed, each containing one version of each of the 20 experimental items plus 23 filler sentences

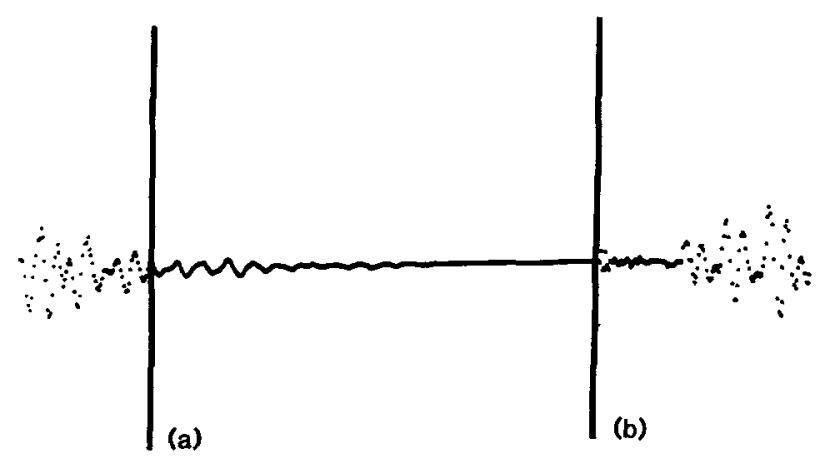

Figure 1. Digital waveform display of the closure portion of [d] in "door" (sentence 16, Appendix 1). (a) Point at which closure splice was made; (b) point at which burst splice was made. 
(listed in Appendix 1); 10 of the filler sentences did not have a word beginning with the specified target, and in the other 13 the target occurred early or late in the sentence, and often on polysyllabic words or parts of speech other than nouns, in order to distract attention from the regularity of the experimental sentences, in which the target words were all monosyllabic nouns occurring near the middle of the sentence. The filler sentences had undergone the same analog-to-digital and digital-to-analog conversion as the experimental sentences, but had not been spliced. The two independent variables, predicted-stress level and splicing position, were counterbalanced across tapes. Thus, predicted-stress level and splicing position were within-group comparisons; the only betweengroup comparison was the tape-condition variable.

Subjects. The subjects were 50 members of the University of Sussex community. Each was paid $70 \mathrm{p}$ for participation in the 15-min experiment. The data from 2 subjects were lost because of equipment failure; 8 other subjects were excluded from the experiment, 6 of them because they missed four or more targets in the experimental sentences, 1 for failing to score significantly above chance on the comprehension test, and 1 because he revealed an extensive knowledge of the Cutler (1976) study and its relation to the present experiment. The remaining 40 subjects comprised four groups of 10 , and each group heard a different one of the four tapes.

Procedure. The subjects were tested in groups of up to four at a time. Each subject was seated in a separate cubicle with a single response button and heard the sentences binaurally over Telephonics TDH-39 headphones. The subjects were told that they should pay attention to the sentences because they would be required to pass a test at the end of the experiment; in addition, they were asked to press the button whenever they heard a word in a sentence beginning with the target sound specified for that sentence. The targets$/ b /, / d /$, and $/ k /$ - varied across sentences, and the particular target was given immediately before each sentence. The click that occurred on the second channel of the tape recording coincident with the release of each target sound started the clock of a PDP-12 computer. The computer recorded the time for each subject to respond.

After the sentences had been presented, the subjects were given a written recognition test. They were required to judge whether or not they had heard each of 20 sentences in the experiment. Ten of the sentences had, in fact, occurred in the experiment, while the other 10 were similar in lexical content to sentences which had occurred. The recognition test sentences are listed in Appendix 2.

\section{Results and Discussion}

The overall mean recognition test score was $80 \%$ for the 40 subjects whose RTs were analyzed. Sixty percent of the errors were false acceptances and $40 \%$ were false rejections, indicating that the subjects had retained much of the content of the sentences they had heard. Mean RTs across subjects and across sentences were calculated for each condition, excluding two responses that were shorter than $150 \mathrm{msec}$ and seven that were longer than $1,500 \mathrm{msec}$. Seven and a quarter percent of the data was lost altogether, as an additional 14 responses were lost due to equipment failure and subjects missed targets on 35 occasions. No one subject was responsible for more than 3 (of 20) missed or rejected responses, and no one item elicited more than 6 (of 40) missed or rejected responses. The sentence means are shown in Table 1.

Two separate analyses of variance were performed on the average scores, one with subjects and one with sentences as random factor, so that the min $\mathrm{F}^{\prime}$ statistic could be calculated. The main effect of predicted stress
Table 1

RT to Phoneme Target (in Milliseconds)

\begin{tabular}{lcc}
\hline & $\begin{array}{c}\text { Predicted } \\
\text { High Stress }\end{array}$ & $\begin{array}{c}\text { Predicted } \\
\text { Low Stress }\end{array}$ \\
\hline Spliced at Closure & 439 & 491 \\
Spliced at Burst & 412 & 464 \\
\hline
\end{tabular}

level was significant $\left[\min F^{\prime}(1,52)=6.00, p<.025\right]$. Neither the main effect of splicing position nor the interaction of splicing position with predicted stress level reached significance on either analysis. In the analysis by subjects, the additional variable of tape condition was not itself statistically significant but did interact significantly with two other comparisons, namely with the splicing position comparison $[F(3,36)$ $=8.12, \mathrm{p}<.001]$ and with the Splicing Position by Predicted-Stress Level interaction $[F(3,36)=3.49$, $p<.05]$. The former effect was due to closure splices producing longer RTs than burst splices for two tapes, shorter RTs for the other tape, and no difference for the fourth. The three-way interaction resulted from the failure of one of the four tapes to show a significant predicted-stress effect in the burst splice condition, although the other three tapes showed the stress effect in that condition and all four tapes showed the stress effect in the closure-splice condition. No systematic differences between the tapes could be discovered to account for these interactions in the analysis by subjects. Note, however, that the probability of Type 1 error is much higher with $F_{1}$ alone than with the min $F^{\prime}$ statistic that we could calculate for the main effects and the interactions between them (Clark, 1973; Forster \& Dickinson, 1976).

As the predicted-stress effect found by Cutler (1976) replicated equally well in both the burst-splice and the closure-splice conditions, it is concluded that the effects of stop closure duration are not crucial to the perceived salience of the target. Thus, the RT difference in the original study could not have been an artifact of the particular splicing method chosen, but must be a function of the prosodic contour applied to the part of the sentence preceding the target. The next study attempted to determine which dimension of prosodic variation was responsible for the predicted-stress effect.

\section{EXPERIMENT 2 EFFECTS OF FUNDAMENTAL FREQUENCY VARIATION}

The sequence of words preceding the target-bearing word in each sentence in these experiments can vary across the two stress conditions on at least three prosodic dimensions: fundamental frequency, duration, and amplitude. We have not, so far, posed the question of which of these sources of prosodic information is necessary or sufficient to enable the prosodic contour to act as an efficient predictor of sentence stress lo- 
cation. Experiment 2 examined this question by the simple expedient of assessing the predictive effect of preceding prosody when one source of prosodic variation has been eliminated. The prosodic dimension chosen was fundamental frequency $\left(\mathrm{f}_{\mathrm{o}}\right)$. This choice was made partly by default, since elimination of $f_{o}$ variation is much easier than elimination of either durational or amplitude variation: Uniform timing requires a prior decision as to which units of speech should be made uniform in length (phonemes? syllables? interstress intervals?), and the information on which to base such a decision is not, to our knowledge, available. Uniform amplitude could be achieved by the use of infinitely peak-clipped speech but presents the problem that different phonemes have different intrinsic amplitudes, so that if they were assigned objectively equal amplitude they would differ considerably in subjective (perceived) amplitude. Monotonizing the $\mathrm{f}_{\mathrm{o}}$ contour to eliminate variation along this dimension is, in contrast, a simple matter. However, there were also grounds for believing that elimination of $f_{o}$ information would indeed disrupt the stress-predictive effect of the prosodic contour. Lea (Note 1) has claimed that $f_{o}$ variation is the most useful cue for the automatic location of sentence stress; thus it appeared that if any prosodic dimension were to prove a necessary component of the prosodic prediction of sentence stress, it would be $f_{o}$.

\section{Method}

Materials. The recording was the same as that used in Experiment 1. All versions of each sentence were again low-pass filtered at $3.5 \mathrm{kHz}$ and digitized at $8 \mathrm{kHz}$ to 10 bits. Each sentence was then coded into LPC parameters, using a program developed by $H$. C. Longuet-Higgins, and two versions were resynthesized, one with the original $f_{o}$ contour and one with a monotone $f_{o}$ at $133 \mathrm{~Hz}$. The rms energy of each 10 -msec section of the speech was the same in the two resyntheses, and each sentence's energy was normalized to give the same maximum waveform amplitude across all sentences.

After resynthesis, the target word was spliced out of the monotone resynthesis of the neutral stress version of each experimental sentence. These target words then replaced the target words in both the $f_{0}$-intact and monotonized resynthesis of each of the other two versions of the corresponding sentences. All four versions of each experimental sentence thus had the same monotone, neutralstress target word. As in Experiment 1, all splices were made with the waveform editing program; the word-initial splices were made at the release of the stop burst. Also as in Experiment 1, clicks were placed on the second channel of the recording coincident with the onset of each target word.

Four experimental tapes were constructed, each containing one version of each of the 20 experimental sentences plus the same 23 filler sentences as in Experiment 1. The filler sentences had been digitized, LPC-coded, and resynthesized, in the same manner as the experimental sentences, but had not been spliced. The two independent variables, predicted-stress level (high vs. low) and $f_{o}$ condition (intact vs. monotonized), were counterbalanced across tapes. Thus, predicted-stress level and $f_{o}$ condition were withingroup comparisons, with the only between-group comparison the tape condition variable.

Subjects. The subjects were 46 members of the University of Sussex community. Each was paid 70 p for participation in the 15min experiment. None of the subjects had participated in Experiment 1 . The data from 3 subjects were lost due to equipment fail- ure, and 3 other subjects were excluded from the experiment, 2 for failing to score significantly above chance on the recognition test and 1 for making too many errors in reacting to target words. The remaining 40 subjects comprised four groups of 10 ; each group heard a different one of the four tapes.

Procedure. The procedure was as in Experiment 1.

\section{Results and Discussion}

The overall mean recognition test score was $81 \%$ for the 40 subjects whose RTs were analyzed; $55 \%$ of the errors were false acceptances and $45 \%$ false rejections. Mean RTs across subjects and across sentences were calculated for each condition, excluding two responses that were shorter than $150 \mathrm{msec}$ and 20 that were longer than $1,500 \mathrm{msec}$. Nine percent of the data was lost altogether-an additional six responses were lost because of equipment failure, and in 44 cases a subject failed to respond to a target. No one subject had more than 3 (of 20) missed or rejected responses, and no one item elicited more than 7 (of 40) missed or rejected responses. The sentence means are shown in Table 2.

Two separate analyses of variance were performed, one with subjects and one with sentences as random factor, so that the min $F^{\prime}$ statistic could be calculated. The main effect of predicted stress level was significant $\left[\min F^{\prime}(1,28)=6.85, p<.025\right]$. Neither the main effect of $f_{o}$ condition nor the interaction of $f_{o}$ condition with predicted-stress level reached significance. In the analysis by subjects, the additional variable of tape condition was not itself statistically significant but did interact with the predicted-stress level variable $[\mathrm{F}(3,36)=4.14, \mathrm{p}<.02]$ because two of the tapes produced a much larger stress effect than the other two. Again, no systematic differences between the tape conditions could be discovered to account for this interaction. (It should be noted that throughout the three experiments-the original study and the two experiments reported here-no tape condition interaction has replicated.)

As the predicted-stress effect replicated equally well in both the $f_{o}$-intact and monotone conditions, it is concluded that $f_{o}$ variation is not a necessary component of the prosodic variation which effectively predicts where sentence stress will fall. The question remains open as to whether either durational or amplitude information is necessary, or whether variation along any one prosodic dimension is sufficient to predict stress location.

Some evidence exists which indicates that durational information may be important. Meltzer, Martin,

Table 2

RT to Phoneme Target (in Milliseconds)

\begin{tabular}{ccc}
\hline & $\begin{array}{c}\text { Predicted } \\
\text { High Stress }\end{array}$ & $\begin{array}{c}\text { Predicted } \\
\text { Low Stress }\end{array}$ \\
\hline Fo Intact $_{\text {Monotone }}$ & 477 & 594 \\
& 472 & 576 \\
\hline
\end{tabular}


Mills, Imhoff, and Zohar (1976) showed that minor temporal displacements of phoneme targets from their originally uttered positions (by as little as $50 \mathrm{msec}$ ) led to an increase in phoneme-monitoring response time. Cutler (Note 2) demonstrated that varying the rhythm of a sentence by splicing into it an interval of silence could produce corresponding changes in response time; a word which was the location of a rhythmic stress beat in the originally recorded, highly rhythmic sentence, but was not once the silent interval had been spliced in, produced faster RTs in the version of the sentence without the silent interval than in the version with the interval, whereas a word which became the location of a rhythmic stress beat when the silent interval was added, although it was not stressed in the original sentence, produced faster RTs in the version of the sentence with the interval than in the version without.

These results establish that phoneme-monitoring $\mathbf{R T}$ is, indeed, sensitive to manipulations of sentence rhythm, and suggest that durational variation may be a good indicator of where stressed syllables will occur. In English, which is a so-called stress-timed language, there is a clear durational difference between stressed and unstressed syllables: Only syllables marked for lexical stress and/or emphatic stress receive their full durational value within an utterance; unstressed syllables tend to be shortened. Not all stressed syllables, however, bear primary sentence stress. Sentence stress is, in a sense, overlaid on rhythmic stress; it emphasizes a word or phrase at the expense of the rest of the sentence and occurs only once or twice in any sentence. Thus, we cannot generalize the phonememonitoring effects of rhythmic stress manipulations to the processing of sentence stress. Following durational cues to the location of rhythmic stress beats would, in general, be a poor strategy for locating primary sentence stress.

In order to check that it would not serve as a possible strategy in the present experiments, we submitted the recordings of the experimental sentences from Experiment 2 to three judges experienced in the analysis of sentence rhythm, and asked them to mark in each sentence the location of rhythmic stress beats and of primary sentence stress. ${ }^{3}$ They were in agreement that the target-bearing words (which, it will be recalled, were all nouns) bore rhythmic stress even in the versions in which they did not bear sentence stress. Thus, if our subjects had been relying on durational cues to the location of rhythmic stress beats, they should have shown no response time difference between the two stress conditions. Since there was a difference, it must be assumed that this aspect of sentence rhythm alone is not responsible for the predictedstress effect. If necessary cues to sentence stress location reside in durational variation, then they must be additional durational cues to sentence stress over and above the rhythmic arrangement of stressed and unstressed syllables.
What seems to be most likely is that the human sentence processor can make extremely flexible use of prosodic information. It may be the case that no single source of prosodic variation will prove to be a necessary cue to where sentence stress will fall, whereas variation along any prosodic dimension will prove sufficiently effective. Certainly, this seems to be true for prosodic cues to the identification of lexical stress and to the location of syntactic bo 7daries. Judgments of lexical stress can be efficien y made on the basis of durational (e.g., Fry, 1955; Nakatani \& Aston, Note 3), amplitude (e.g., Lieberman, 1960) or $\mathrm{f}_{\mathrm{o}}$ information (e.g., Fry, 1958; Lieberman, 1960; Morton \& Jassem, 1965); judgments of syntactic boundary location can be based on $\mathrm{f}_{\mathrm{o}}$ falls (Collier \& 't Hart, 1975; Lea, Note 4) or on interstress interval lengthening (Lehiste, Olive, \& Streeter, 1976; Scott, 1980). If prosodic cues to sentence stress location are equally catholic, it is not surprising that we have found $f_{o}$ information to be unnecessary despite the fact that Lea (Note 1) has reported it to be sufficient.

With natural speech, listeners presumably have the option of using prosodic information from more than one source. Gay (1978) has argued that lexical stress perception in natural speech is based on the employment of multiple cues, and Streeter (1978) has shown that listeners can use $f_{o}$ and durational cues to the presence of syntactic boundaries independently and additively. Similarly, when $f_{o}$ cues to sentence stress location are present, the sentence processor may well make use of them; the present study has shown, however, that it is flexible enough to locate sentence stress equally well without them.

\section{REFERENCE NOTES}

1. Lea, W. A. Prosodic aids of speech recognition: V. A summary of results to date (Tech. Rep. No. PX 11087). St. Paul, Minn: Sperry Univac, 1974.

2. Cutler, A. Rhythmic determinants of perceived stress. Paper presented to the Acoustical Society of America, 89th meeting, Austin, Texas, April 1975.

3. Nakatani, L., \& Aston, C. H. Perceiving stress patterns in words in sentences. Paper presented to the Acoustical Society of America, 95th meeting, Providence, Rhode Island, May 1978.

4. Lea, W. A. Prosodic aids to speech recognition: II. Syntactic segmentation and stressed syllable location (Tech. Rep. No. PX 10232). St. Paul Minn: Sperry Univac, 1973.

\section{REFERENCES}

Clark, H. H. The language-as-fixed-effect fallacy: A critique of language statistics in psychological research. Journal of Verbal Learning and Verbal Behavior, 1973, 12, 335-359.

Collier, R., \& 'T HART, J. The role of intonation in speech perception. In A. Cohen \& S. Nooteboom (Eds.), Structure and process in speech perception. Heidelberg: Springer, 1975.

Cutler, A. Phoneme-monitoring reaction time as a function of preceding intonation contour. Perception \& Psychophysics, $1976,20,55-60$.

Cutler, A., \& Fodor, J. A. Semantic focus and sentence comprehension. Cognition, 1979, 7, 49-59. 
Cutrer, A., \& Foss, D. J. On the role of sentence stress in sentence processing. Language \& Speech, 1977, 20, 1-10.

Cutler, A., \& Isard, S. D. The production of prosody. In B. Butterworth (Ed.), Language production. London: Academic Press, 1980.

Forster, K. I., \& Dickinson, R. G. More on the language-asfixed-effect fallacy: Monte Carlo estimates of error rates for $F_{1}, F_{2}, F^{\prime}$ and min $F^{\prime}$. Journal of Verbal Learning and Verbal Behavior, 1976, 15, 135-142.

FrY, D. B. Duration and intensity as physical correlates of linguistic stress. Journal of the Acoustical Society of America, $1955,35,765-769$.

FrY, D. B. Experiments in the perception of stress. Language \& Speech, 1958, 1, 120-152.

GAY, T. Physiological and acoustic correlates of perceived stress. Language \& Speech, 1978, 21, 347-353.

LADD, D. R. The structure of intonational meaning. Bloomington: Indiana University Press, 1980.

Lehiste, I., Olive, J., \& Streeter, L. A. The role of duration in disambiguating syntactically ambiguous sentences. Journal of the Acoustical Society of America, 1976, 60, 1199-1202.

Lieberman, P. Some acoustic correlates of word stress in American English. Journal of the Acoustical Society of America, $1960,32,451-454$.

Mehler, J., Segui, J., \& Carey, P. Tails of words: Monitoring ambiguity. Journal of Verbal Learning and Verbal Behavior, 1978, 17, 29-35.

Meltze R, R. H., Martin, J. G., Mills, C. B., Imhoff, D. L., \& ZohaR, D. Reaction time to temporally displaced phoneme targets in continuous speech. Journal of Experimental Psychology: Human Perception and Performance, 1976, 2, 277-290.

Morton, J., \& J ASSEM, W. Acoustic correlates of stress. Language \& Speech, 1965, 8, 159-181.

Newman, J. E., \& Dell, G. S. The phonological nature of phoneme-monitoring: A critique of some ambiguity studies. Journal of Verbal Learning and Verbal Behavior, 1978, 17, 359-374.

Schmerling, S. F. Aspects of English sentence stress. Austin: University of Texas Press, 1976.

Scott, D. R. Perception of phrase boundaries. PhD thesis, University of Sussex, 1980.

Shields, J. L., McHugh, A., \& Martin, J. G. Reaction time to phoneme targets as a function of rhythmic cues in continuous speech. Journal of Experimental Psychology, 1974, 102, 250-255.

Streeter, L. A. Acoustic determinants of phrase boundary detection. Journal of the Acoustical Society of America, 1978, 64, 1582-1592.

\section{NOTES}

1. See Cutler and Isard (1980), Ladd (1980), and Schmerling (1976) for arguments that sentence stress assignment is a semantic/ pragmatic rather than a syntactic function.

2. We are grateful to $R$. Diehl for bringing this potential confound to our attention.

3. We are grateful to A. J. Donovan, S. D. Isard, and D. R. Scott for their assistance in this task.

\section{APPENDIX 1}

\section{Experimental Sentences Used in Both Experiments}

The target-bearing word is italicized. In sentences in which different endings were used in the high- and low-stress versions, the first ending is for the version with the high-stress on the target word and the second is for the low-stress version.

(1) She managed to remove the dirt from the rug, but not $\left\{\begin{array}{l}\text { the grass stains. } \\ \text { from their clothes. }\end{array}\right.$

(2) The head cashier said the bag contained money, $\left\{\begin{array}{l}\text { and so did the strongbox. } \\ \text { although his colleagues disagreed with him. }\end{array}\right.$

(3) John decided that he would take the boat down the river, $\left\{\begin{array}{l}\text { although flying would have saved him a day. } \\ \text { since he had enjoyed the trip up so much. }\end{array}\right.$

(4) The top experts were all unable to break the code the spy had used.

(5) The agent was not surprised to find a bug hidden in his telephone.

(6) She felt very guilty about the debt she owed him, $\left\{\begin{array}{l}\text { and felt she should try harder to pay it. } \\ \text { but she still made no attempt to pay it. }\end{array}\right.$

(7) The couple had quarrelled over a book they had $\left\{\begin{array}{l}\text { read. } \\ \text { n't even read. }\end{array}\right.$

(8) The politician reminded his friend of a bet they had made. 
(9) That summer 4 years ago I ate roast $d u c k$ for $\left\{\begin{array}{l}\text { the first time. } \\ \text { every meal. }\end{array}\right.$

(10) I had been thinking about buying another coat before $\left\{\begin{array}{l}\text { the winter. } \\ \text { you mentioned it. }\end{array}\right.$

(11) Unfortunately not enough attention was paid to the cost before the party, $\left\{\begin{array}{l}- \\ \text { and too much afterwards. }\end{array}\right.$

(12) I wanted to hire the band to give the place some atmosphere, $\left\{\begin{array}{l}\text { and now it seems that's not enough. } \\ \text { not to drive everyone away. }\end{array}\right.$

(13) My father was very fond of the dog he had, but $\left\{\begin{array}{l}\text { he couldn't stand the cats. } \\ \text { my mother hated it. }\end{array}\right.$

(14) Down on the farm we used a cart for bringing feed to the animals, $\left\{\begin{array}{l}\text { since we didn't have anything else to use. } \\ \text { but we never rode around in it. }\end{array}\right.$

(15) In many country houses they still sound a bell for dinner, $\left\{\begin{array}{l}\text { and expect dinner guests to wear evening clothes. } \\ \text { although other meals are less formal. }\end{array}\right.$

(16) The policemen investigating the crime suggested that the door could have been forced open $\left\{\begin{array}{l}\text { as well as the window. } \\ \text { not left unlocked by } \\ \text { the owner. }\end{array}\right.$

(17) The sports teacher made a point of riding her bike to work, $\left\{\begin{array}{l}\text { to set a good example. } \\ \text { although she never took it to the shops. }\end{array}\right.$

(18) The ambassador's wife wanted to hire a new cook before they moved to their new post $\left\{\begin{array}{l}\text { and perhaps a maid or two } \\ \text { as well. } \\ \text { rather than try to find one } \\ \text { there. }\end{array}\right.$

(19) The survey reports that university students are drinking more beer this year $\left\{\begin{array}{l}\text { and more wine as well. } \\ \text { than in any one of the previous five years. }\end{array}\right.$

(20) It is unlikely that the date on which the battle occurred will be remembered, although the $\left\{\begin{array}{l}\text { outcome will not be } \\ \text { forgotten. } \\ \text { signing of the treaty will } \\ \text { not be forgotten. }\end{array}\right.$

\section{Filler Sentences Used in Both Experiments}

(1) Instead of taking the trip to Spain as he had planned, Matthew decided to buy a second-hand car.

(2) The art gallery had several paintings which on close inspection turned out to be forgeries.

(3) The bulbs on the Christmas tree would not light up since the wiring was faulty.

(4) Radio programmes are considered by some people to be less interesting than they were in the days before television.

(5) His pet rabbit escaped from the garden after a visiting salesman had left the gate open.

(6) The factory location was particularly desirable because it was so close to the motorway.

(7) Several changes have recently been made in the society's constitution and regulations.

(8) The newlyweds received so many presents that they had to move into a larger flat.

(9) The member of parliament feared that his chances of re-election had been damaged by the newspaper's allegations. 
(10) The university vice-chancellor's opinion on the proposed cuts was reported on the evening news.

(11) My six cousins seemed to have every intention of staying all summer, till I put my foot down.

(12) The graffiti in the underground station greatly amused the tourists.

(13) His old Volvo broke down while he was on holiday in Wales.

(14) All of those at the meeting resolved to take greater case of the environment in future.

(15) The old folks' club had gone on its regular Friday afternoon bus trip.

(16) She finally moved to Sussex after fifty years of grumbling about the cold in Scotland.

(17) Several people were arrested during a demonstration in front of the hall where the group had convened.

(18) The captain of the expedition refused to turn back despite the illness of two team members.

(19) My uncle spent most of his time on the deck of the yacht, surrounded by beautiful women.

(20) The victim of the gang's vicious attack had a gash on his face and cuts on his arms and back.

(21) After moving house four times the family eventually found a place they really liked.

(22) The young naval officer was not at all happy about his assignment to the destroyer.

(23) Benjamin was a most pleasant and unassuming lad, till he went into the army.

APPENDIX 2

\section{Recognition Test}

(1) The art gallery had several paintings which on close inspection turned out to be forgeries.

(2) The university vice-chancellor's opinion on the proposed cuts was reported on the evening news.

(3) His pet rabbit had been stolen by a travelling salesman.

(4) Unfortunately not enough attention was paid to the cost before the party and too much afterwards.

(5) Benjamin was a most pleasant and unassuming lad, till he went into the army.

(6) She moved to Sussex although she would have much preferred to remain in Scotland.

(7) The policeman investigating the crime suggested that the window had been broken open with a crowbar.

(8) My cousins were invited to stay all summer, but they turned the offer down.

(9) John decided that he would take the boat down the river, although flying would have saved him a day.

(10) The old folks' club had cancelled the bus trip because of the snow.

(11) The top experts were all unable to break the code the spy had used.

(12) In many country houses they still sound a bell for dinner, and expect dinner guests to wear evening clothes.

(13) His old Volvo broke down while he was on holiday in Wales.

(14) My father was very fond of the dog that he had, but my mother hated it.

(15) The bulbs on the Christmas tree would not light up since the wiring was faulty.

(16) I had been thinking about buying another coat before you mentioned it.

(17) Matthew had plans for sailing to Spain in his luxury yacht.

(18) She felt very guilty about the debt she owed him, and felt she should try harder to pay it.

(19) University students and young people in general are drinking more wine than ever before.

(20) The agent was not surprised to find a bug hidden in his telephone. 